\title{
Differential hRad17 expression by histologic subtype of ovarian cancer
}

\author{
Jennifer L Young ${ }^{2 *}$, E Colin Koon ${ }^{3}$, Joseph Kwong ${ }^{4}$, William R Welch ${ }^{5}$, Michael G Muto ${ }^{1}$, Ross S Berkowitz and \\ Samuel C Mok ${ }^{6}$
}

\begin{abstract}
Background: In the search for unique ovarian cancer biomarkers, ovarian specific cDNA microarray analysis identified hRad17, a cell cycle checkpoint protein, as over-expressed in ovarian cancer. The aim of this study was to validate this expression.

Methods: Immunohistochemistry was performed on 72 serous, 19 endometrioid, 10 clear cell, and 6 mucinous ovarian cancers, 9 benign ovarian tumors, and 6 normal ovarian tissue sections using an anti-hRad17 antibody. Western blot analysis and quantitative PCR were performed using cell lysates and total RNA prepared from 17 ovarian cancer cell lines and 6 normal ovarian epithelial cell cultures (HOSE).

Results: Antibody staining confirmed upregulation of hRad17 in $49.5 \%$ of ovarian cancer cases. Immunohistochemistry demonstrated that only $42 \%$ of serous and $47 \%$ of endometrioid subtypes showed overexpression compared to $80 \%$ of clear cell and 100\% of mucinous cancers. Western blot confirmed overexpression of hRad17 in cancer cell lines compared to HOSE. Quantitative PCR demonstrated an upregulation of hRad17 RNA by 1.5-7 fold. hRad17 RNA expression differed by subtype.
\end{abstract}

Conclusions: hRad17 is over-expressed in ovarian cancer. This over-expression varies by subtype suggesting a role in the pathogenesis of these types. Functional studies are needed to determine the potential role of this protein in ovarian cancer.

\section{Background}

Ovarian cancer is the most deadly of all gynecologic malignancies [1]. Because ovarian cancer is diagnosed in Stage III or IV in $80 \%$ of cases, the prognosis is poor with only a $44 \%$ overall survival rate [1]. However, when ovarian cancer is diagnosed in the earliest stage, survival approaches $90 \%$. Therefore we continue to search for better methods of early detection and for new therapeutic targets. Microarray technology allows the simultaneous comparison of two different populations to identify unique gene expression profiles. Use of microarray technology has been instrumental in identifying new genes possibly involved in the pathogenesis of ovarian cancer as well as secretory proteins that may have clinical utility as serum markers [2-5]. An ovarian-specific complementary DNA (cDNA) chip showed differential expression of hRad17 in

\footnotetext{
* Correspondence: youngj|@musc.edu

${ }^{2}$ Division of Gynecologic Oncology, Department of Obstetrics and Gynecology, Medical University of South Carolina, Charleston, SC, USA Full list of author information is available at the end of the article
}

cancer cells of long term survivors compared to short term survivors with Stage IIIC ovarian cancer [6].

hRad17 is the human homologue of a cell cycle checkpoint protein that was originally identified in yeast and is normally expressed in the human testis $[7,8]$. This protein is involved in DNA damage recognition and repair and is associated with accumulation of p53 [9]. hRad17 is a nucleolar protein that disperses after DNA damage $[10,11]$ and is activated by ATR-mediated phosphorylation [12-15]. This protein interacts with DNA polymerase $\varepsilon$ [10] and serves as the clamp loader for the hRad 9-1-1 sliding clamp polymerase [16-19]. Both mechanisms are important for G2 checkpoint during cell replication. Recent data also demonstrates an interaction with DNA ligase I [20]. Loss of the function of hRad17 or aberrant expression may lead to malfunction of DNA repair and ultimately the development of cancer [21,22]. Alternatively, elevated expression in the setting of cancer may lead to increased resistance to DNA-damaging agents.
C Biomed Central 
These checkpoint proteins may serve as important therapeutic targets [23].

Prior studies have shown that hRad17 is upregulated in other cancers including colon, breast, and lung cancer $[7,14,24]$ but no studies have thus far been conducted in ovarian cancer. The aim this study is to validate the over-expression of hRad17 in ovarian cancer and correlate this data with clinical outcomes.

\section{Methods}

\section{Cell lines and tissue samples}

All patient-derived specimens were collected and archived under protocols approved by the Brigham and Women's Hospital Human Subjects Committee, Brigham and Women's Hospital, Boston, MA, or as an approved use of discarded human materials as previously described [4]. All 17 ovarian cancer cell lines (CaOV3, DOV13, MCAS, OVCA3, OVCA420, OVCA429, OVCA432, OVA433, OVCA633, PEO4, SKOV3, TOV21G, RMG-1, ES2, TOV112 D, RMUG-L, RMUG-S) and 6 human ovarian surface epithelium (HOSE) cultures (HOSE2105, HOSE2107, HOSE 2139, HOSE 2166, HOSE 2170, HOSE 2177) were obtained and grown in conditions as previously described [25]. RNA was extracted from individual or pooled cell lines by using micro RNA extraction kit as described by the manufacturer (Qiagen, Valencia, CA) and quantified by fluorometry (Gemini Bio-Products, Inc, Calabasas, VA.). Clinicopathologic information, including diagnosis, disease stage and grade, and months survival, was collected from the patients' charts. All pathologic samples were re-reviewed for confirmation of histologic type and diagnosis.

\section{RNA extraction and real-time quantitative polymerase chain reaction}

Quantitative RT-PCR was performed on total RNA prepared from 11 serous, 3 clear cell, 1 endometrioid, and 2 mucinous ovarian cancer cell lines as well as 6 normal ovarian epithelial cell cultures. For the quantitative RTPCR studies a total of $1 \mu \mathrm{L}(0.1 \mu \mathrm{g})$ cDNA was used in a $25 \mu \mathrm{L}$ PCR mix containing 1X SYBR PCR buffer, $3 \mathrm{mM}$ $\mathrm{MgCl}_{2}, 0.8 \mathrm{mM} \mathrm{dNTP}$, and $0.025 \mathrm{U} / \mu \mathrm{L}$ AmpliTaq Gold (PE Applied Biosystems, Foster City, CA). Amplification was then performed in duplicate using primer sets purchased from Sigma GenoSys (The Woodlands, TX) (forward primer: 5'-TCCCTCTGAAGCGACACTTT-3', reverse primer: 5'-AGTGGCTTGAGTGGGTTCAC-3') and glyceraldehyde-3-phosphate dehydrogenase (GAPDH) for normalization of input RNA in an ABI PRISM 5700 Sequence Detector (PE Applied Biosystems). RT-PCR was run with denaturation for 10 minutes at $95^{\circ} \mathrm{C}$ then 40 PCR cycles of denaturation at $95^{\circ} \mathrm{C}$ for 15 seconds and finally annealing or extension at $60^{\circ} \mathrm{C}$ for 1 minute. The relative level of hRad17 for each sample was calculated as described [4]. In brief, the relative amount of PCR products generated from each primer set was determined on the basis of the $C_{t}$ value. GAPDH was used to normalize the quantity of RNA used. Its $C_{t}$ value was then subtracted from that of each target gene to obtain the $\Delta C_{t}$ value. The difference between the $\Delta C_{t}$ value and the calibrator $\left(\Delta C_{t}\right.$ of sample HOSE 21) was determined as the $\Delta \Delta C_{t}$. The representative quantitative value was expressed as $2^{-\Delta \Delta C t}$. The Mann Whitney U test for nonparametric data was used to compare the distributions of all cancer cell lines to normal HOSE as well as the serous cancer cell lines to normal HOSE using SAS software version 9.1.3 (SAS Institute Inc, Cary, NC)

\section{Western blot analysis}

Western blot analyses were performed using ovarian tumor cell lysates from 4 ovarian cancer cell lines (ES2, PEO4, DOV13, and OVCA 429) and 2 normal ovarian epithelial cell cultures (HOSE 667 and HOSE 21) using the mouse monoclonal anti-hRad17 antibody (provided by Dr. Lan Bo Chen's laboratory at Dana Farber Cancer Institute, Boston, MA) previously described in immunohistochemistry on breast and colon tissues [7,24], and a rabbit monoclonal antibody against phosphorylated or activated hRad17 (Santa Cruz Biotechnology, Inc, Santa Cruz, CA). In brief, a total of $25 \mu \mathrm{g}$ protein for each sample were electrophoresed on a 10\% SDS-PAGE gel. They were then transferred to a PVDF membrane for 1 hour. Membrane was blocked overnight in 5\% milk in washing buffer (TBST, created from $10 \mathrm{~mL} 1 \mathrm{M}$ Tris, $20 \mathrm{~mL}$ of $5 \mathrm{M} \mathrm{NaCl}$, and $1 \mathrm{~mL}$ Tween 20 to volume of $1 \mathrm{~L})$ at $4^{\circ} \mathrm{C}$ and incubated manually with an anti-hRad17 or an anti-phosphorylated hRad17 using 1:1000 dilution or $5 \mu \mathrm{L}$ in $5 \mathrm{~mL} 5 \%$ milk in washing buffer for 1 hour at room temperature followed by a wash in TBST for $45 \mathrm{~min}$. The membrane was then incubated with secondary antibody (either goat-anti-mouse for anti-hRad17 or goat anti-rabbit for anti-hRad17-phos) $0.5 \mu \mathrm{L} / \mathrm{mL}$ in washing buffer. The membrane was then again washed for $45 \mathrm{~min}$. Immunoreactivity was detected using the ECL Chemiluminescence System (Amersham, Piscataway, NJ). For normalization of protein loading, the same membrane was incubated with an anti- $\beta$-actin monoclonal antibody (Sigma, St. Louis, MO).

\section{Immunohistochemistry}

Immunostaining was performed using a mouse monoclonal anti-hRad17 antibody as described above. Tissue sections were prepared from 72 serous, 19 endometrioid, 10 clear cell, and 6 mucinous ovarian cancer cases in addition to 9 benign ovarian epithelial tumors and 6 normal ovaries. The slides were first incubated at $60^{\circ} \mathrm{C}$ overnight. They were then deparaffinnized in xylene and rehydrated in graded ethanol. The slides 
were then washed in Tris-buffered saline (TBS) for 5 minutes. Blocking serum was made using $10 \mathrm{~mL}$ TBS with $1 \%$ bovine serum albumin (BSA). Slides were incubated with the blocking serum for 30 minutes and washed prior to incubation with anti-HRad17 antibody $(2 \mu \mathrm{g} / \mathrm{mL})$ for 1.5 hours. Slides were then washed in TBS for $20 \mathrm{~min}$. The slides were then stained using the Universal DakoCytomation EnVision System-AP with Fast Red Substrate-Chromogen, and EnVision Labeled Polymer, Alkaline Phosphatase (DakoCytomation, Dako, Denmark) as described in the product's directions. First the slides were incubated with alkaline phosphatase labeled polymer for 30 minutes, washed in TBS for $20 \mathrm{~min}$, and incubated with the Fast Red chromogen solution for 15 minutes. After washing in water, each slide was then mounted and the immunoreactivity was quantified using a semi-quantitative scoring system described previous [26]. A weighted score was obtained by multiplying the score (0-3) for intensity on a scale of 0 for no staining and 3 for maximum intensity of red staining and the score for percentage stained (0-4). For percentage stained 0 represented no staining of the specimen, 1 equal to less than $25 \%$ stained, 2 equal to $25-50 \%$ stained, 3 equal to $50-75 \%$ of specimen stained, and 4 equal to $>75 \%$ of specimen staining positive. A mean score was then established at 3 . Scores $\geq 3$ were considered positive for hRad17 expression and scores $<3$ were considered negative for expression. Scores were compared using Kruskal-Wallis analysis for nonparametric data. Representative photomicrographs were recorded by digital camera (Optronic, Inc., Muskogee, $\mathrm{OK})$.

\section{Correlation with Patient Survival}

Clinical survival data was obtained from 72 cases of Stage 3, Grade 3 serous ovarian cancer from 1990-2003 starting with the date of the initial operation to the most recent visit. 66 of 72 patients were deceased at the time that the charts were reviewed. Patients were further divided into optimally and suboptimally debulked patients as defined by $<2 \mathrm{~cm}$ nodules of residual disease at the end of surgery. Survival data was correlated with hRad17 over-expression and results obtained were examined by Kaplan Meier survival analysis. Statistical significance was determined by the log rank test.

\section{Results}

\section{Quantitative RT-PCR}

Quantitative real-time PCR was performed on total RNA prepared from 11 serous, 3 clear cell, 1 endometrioid, and 2 mucinous ovarian cancer cell lines as well as 6 normal ovarian epithelial cell cultures. RT-PCR demonstrated an upregulation of hRad17 RNA by 1.5-7 fold relative to HOSE. Fourteen of seventeen ovarian cancer cell lines showed up-regulation of hRad17 RNA compared to one of six normal ovarian epithelial cell cultures, $\mathrm{p}=0.0013$. In addition, PCR confirmed differential expression of hRad17 RNA by subtype with $2 / 2$ mucinous and $3 / 3$ clear cell cancer lines compared to $8 / 11$ serous tumor cell lines. Mucinous and clear cell types all have 2-4 fold over-expression (Figure 1). While the mucinous and clear cell groups were too small for comparison, the serous cancer cell lines were also found to have a significantly different distribution of hRad17 compared to normal with $\mathrm{p}=0.0091$.

\section{Western blot Analysis}

Next, western blot was used to confirm over-expression of total and phosphorylated hRad17 protein in 4 ovarian cancer cell lines compared to 2 normal HOSE cell lines. Three of four ovarian cancer cell lines were positive for over-expression of hRad17 compared to 0/2 normal HOSE. Further, ES2 and PEO4 were strongly positive for activated hRad17 and DOV13 and OVCA 429 were weakly positive for hRad17 expression compared to no expression in 2 normal HOSE cell lines (Figure 2).

\section{Immunohistochemistry}

Immunostaining of hRad17 protein was performed using a mouse monoclonal anti-hRad17 antibody previously described in immunohistochemistry on breast and colon tissues $[7,24]$. Tissue sections were stained from 72 serous, 19 endometrioid, 10 clear cell, and 6 mucinous ovarian cancers in addition to 9 benign ovarian epithelial tumors and 6 normal ovaries. Over-expression was defined by a standard scoring system to judge the intensity and percentage stained and each slide was given a score of hRad17 expression by two independent reviewers who were blinded to the histologic type prior to review. Antibody staining confirmed upregulation of hRad17 in 53 of 107 (49.5\%) ovarian carcinomas.

Immunohistochemistry further demonstrated differential expression among different subtypes of ovarian cancer. While only $42 \%$ (30/72) of papillary serous and $47 \%$ $(9 / 19)$ of endometrioid subtypes showed over-expression, $80 \%(8 / 10)$ of clear cell and $100 \%(6 / 6)$ of mucinous tumors over-expressed hRad17 (Figure 3). hRad17 over-expression was significantly higher in mucinous and clear cell subtypes compared to serous cancer ( $\mathrm{p}=$ $0.002, \mathrm{p}=0.005$ respectively).

In addition, there were noted to be clear differences in the pattern of hRad17 expression between ovarian cancer and benign tissue as well as among the different subtypes of ovarian cancer (Table 1). While in benign ovarian epithelium hRad17 staining demonstrated a nuclear location only consistent with the positive controls, the papillary serous tumors exhibited hRad17 staining in the 


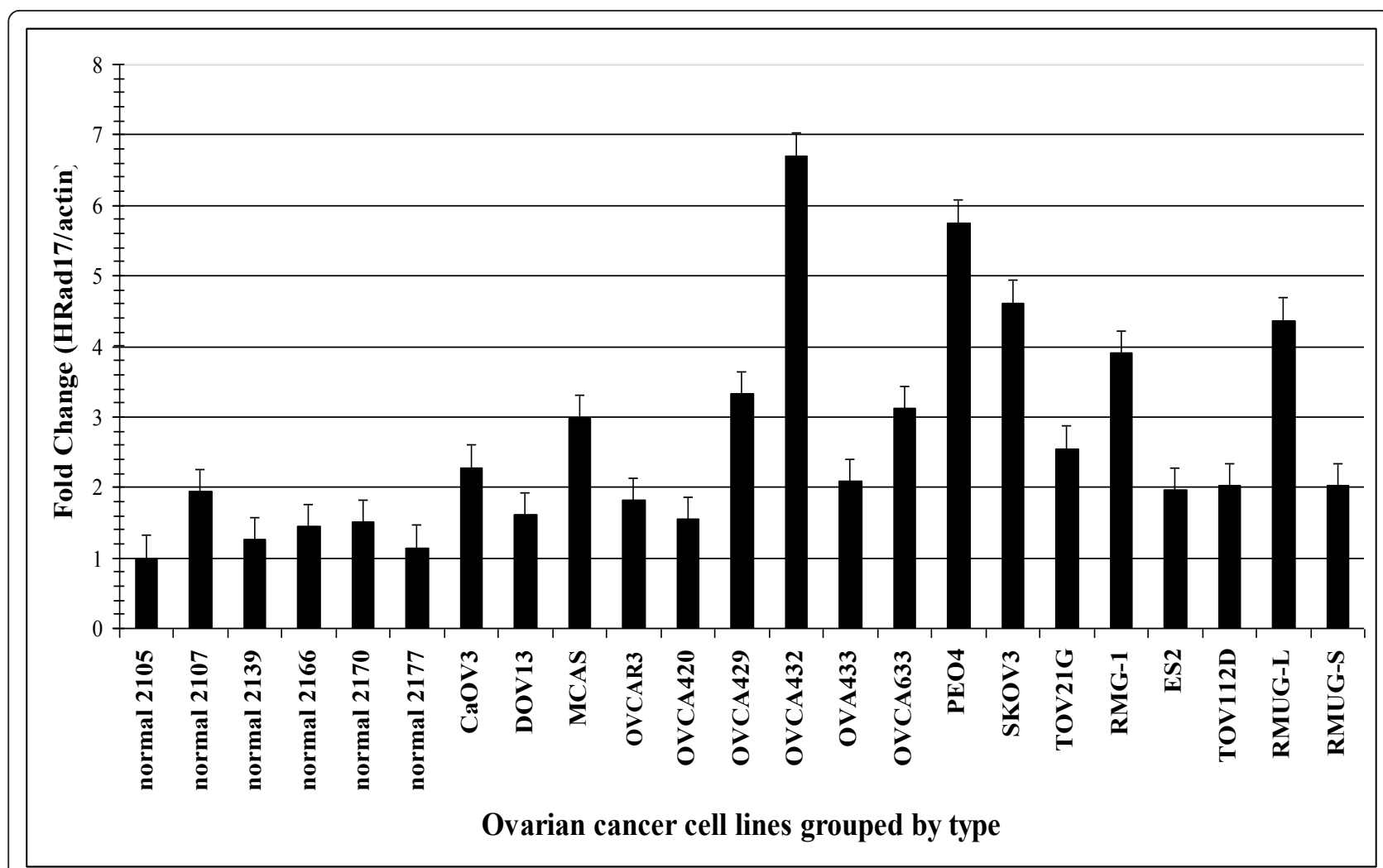

Figure 1 RT-PCR showing hRad17 over-expression by ovarian cancer cell line compared to HOSE. (TOV112 D is an endometrioid type ovarian cancer cell line.).

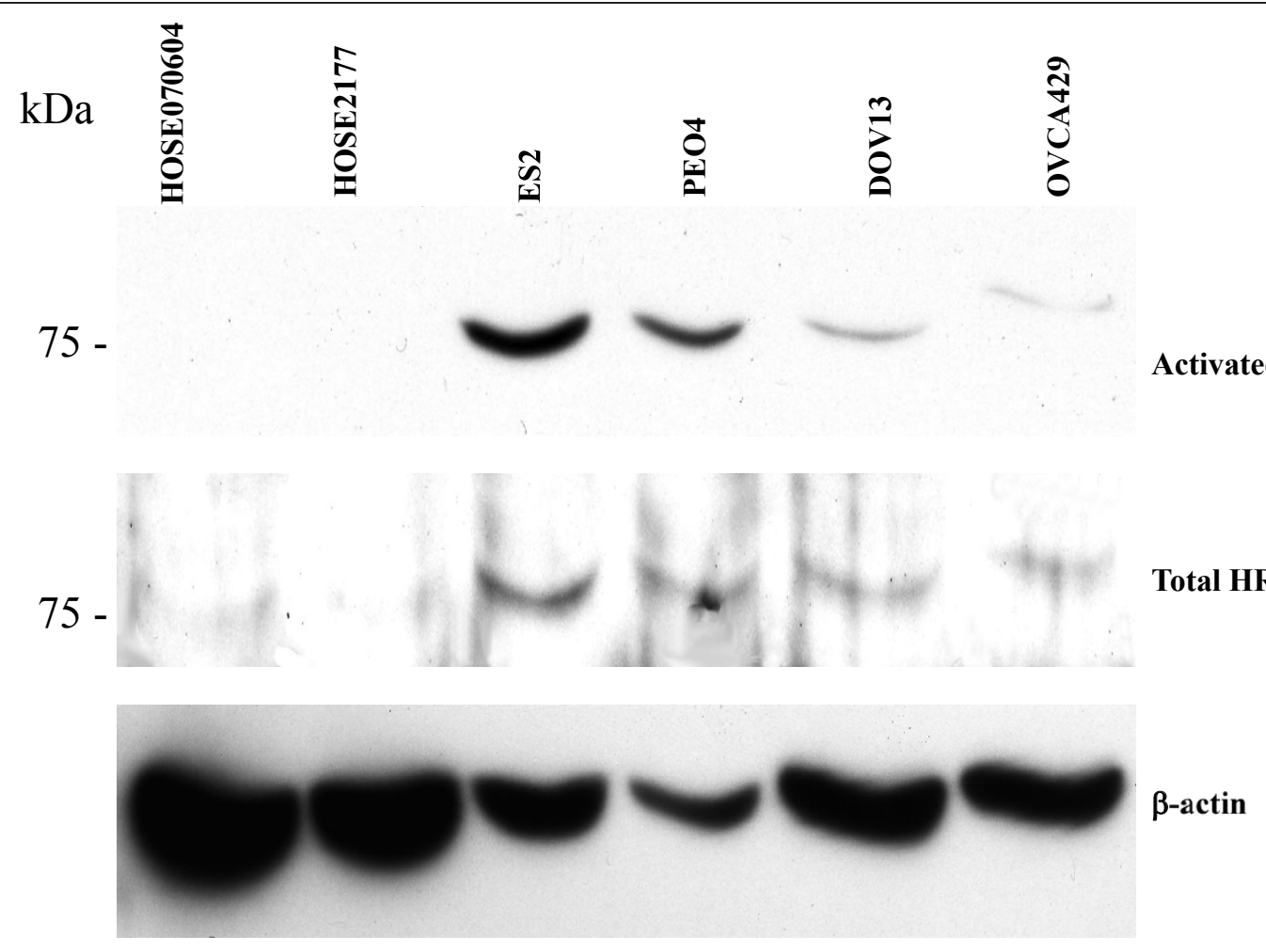

Figure 2 Western blot of ovarian carcinoma cell lysates showing elevated expression of both total and activated hRad17. 


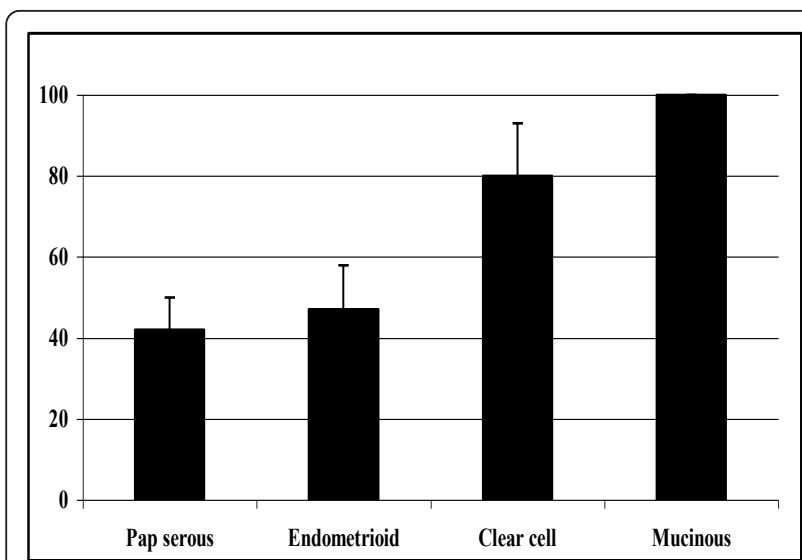

Figure 3 Percentage overexpression hRad 17 determined by immunohistochemistry quantitative analysis comparing different subtypes of ovarian cancer.

cytoplasm as well as in the nucleus. Mucinous cancers were also strongly positive in the nucleus and the cytoplasm. The clear cell type showed no nuclear staining but demonstrated an unusual deeply stained speckled pattern in the cytoplasm (Table 1). Representative photomicrographs were taken and are shown in Figure 4.

\section{Patient Survival Analysis}

Patient survival data was collected on the 72 Grade 3, Stage IIIC serous cancers that were stained for hRad17. Kaplain-Meier curves were generated to compare hRad17 over-expression to patient survival (Figure 5). There was no significant difference of hRad17 expression when comparing short-term survivors to long-term survivors with Stage IIIC, Grade 3/3 serous ovarian cancer. When patients were further divided into optimally and suboptimally debulked (as defined by $<2 \mathrm{~cm}$ residual disease at the completion of surgery) there was still no correlation found between hRad17 over-expression and patient survival (data not shown).

Table 1 Pattern of hRad17 staining by ovarian cancer subtype

\begin{tabular}{|c|c|c|c|}
\hline $\begin{array}{l}\text { Ovarian cancer } \\
\text { subtype }\end{array}$ & $\begin{array}{c}\text { Number of } \\
\text { cases }\end{array}$ & hRad17 staining & $\begin{array}{c}\text { Percent } \\
\text { over- } \\
\text { expressing } \\
\text { hRad17 }\end{array}$ \\
\hline Benign & 9 & Nuclear & $13 \%$ \\
\hline Serous & 72 & $\begin{array}{l}\text { Nuclear and } \\
\text { cytoplasmic }\end{array}$ & $42 \%$ \\
\hline Endometrioid & 19 & Cytoplasmic & $47 \%$ \\
\hline Clear cell & 10 & Cytoplasmic & $80 \%$ \\
\hline Mucinous & 6 & $\begin{array}{c}\text { Nuclear, cytoplasmic, } \\
\text { and stromal }\end{array}$ & $100 \%$ \\
\hline
\end{tabular}

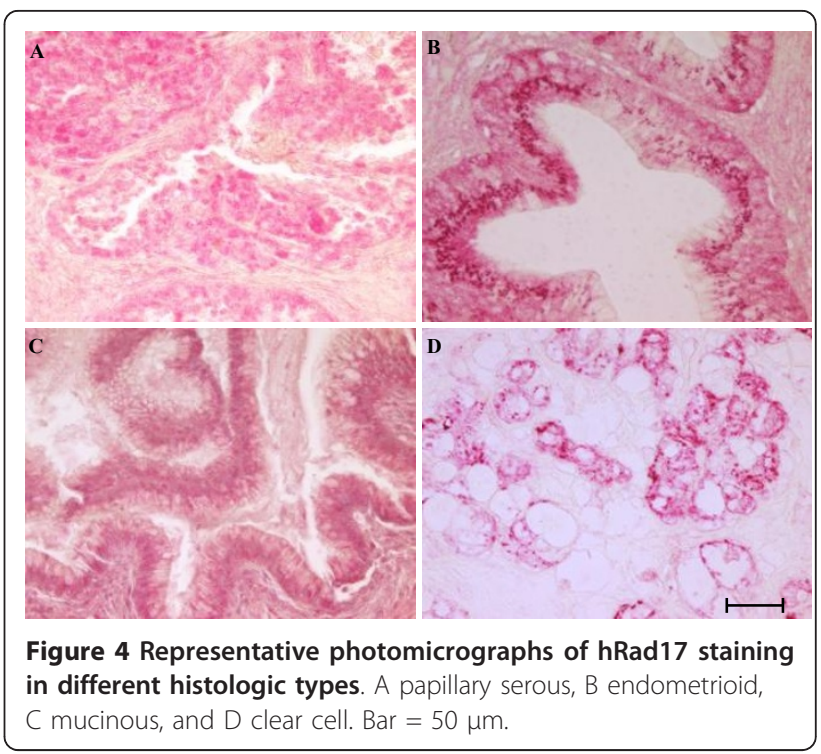

\section{Discussion}

Bao et al. initially cloned hRad17 after discovering a unique protein that was differentially expressed in colon cancer over normal colonic tissue [7]. hRad17 is overexpressed in $54.7 \%$ of all breast cancers and in $68 \%$ of those breast cancers with lymph node metastases [24]. Similarly, comparison of non-small cell lung cancer to normal tissue has shown overexpression of hRad17 [14] and demonstrated a significant correlation of hRad17 expression with the presence of lymph node metastases [27]. In contrast, hRad17 is down-regulated in head and neck cancers compared to normal oral mucosa likely secondary to gene deletion, possibly contributing to increased rates of DNA mutations in head and neck tumors [28].

Our study found that hRad17 is over-expressed in ovarian cancer, as seen in breast, colon, and lung cancer. Further, the pattern of expression differs among subtypes of ovarian epithelial cancers. Unlike studies in breast and lung cancer that found over-expression correlated with metastases, we did not find that hRad17 over-expression correlated with survival in a subgroup of patients with Stage IIIC serous ovarian cancer. Given this protein's role as in the cell cycle checkpoint, upregulation of hRad17 may increase a tumor's resistance to platinum agents which rely on DNA damage for cell death. This hypothesis would need to be tested in a larger group of patients with mucinous and clear cell tumors. Alternatively, over-expression may represent accumulation of a nonfunctional protein. Future studies including staining the tissue sections with Ki67 may help to elucidate this unusual staining pattern. We would hypothesize that Ki67 overexpression would be 


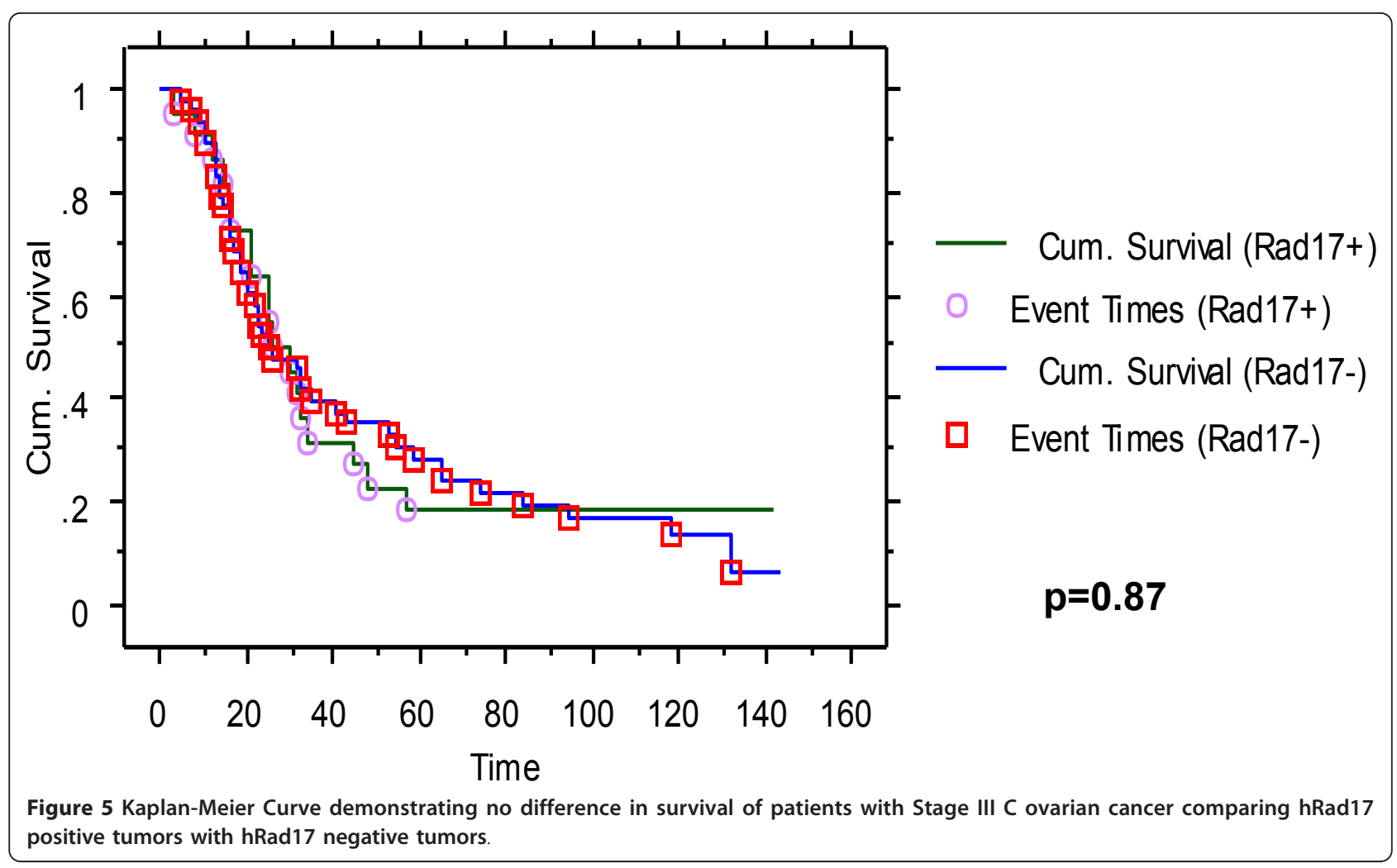

more likely in tissues showing predominately nuclear staining.

Other studies have suggested that abnormal expression or distribution of hRad17 may lead to a loss of function as a DNA damage repair protein. hRad17 has been characterized as a nucleolar protein when functional in DNA repair. We found differential expression of this protein in both the cytoplasm and nucleus depending on the histologic type. Dispersion of hRad17 may correlate with a loss of function as a DNA repair protein. Functional studies are needed to characterize the role of hRad17 in these tumors, both in the nucleus and the cytoplasm.

This study consisted of a small sample set for comparison of survival data and a larger number of cases may show a significant difference in expression between short-term and long-term survivors. Further, the use of immunohistochemistry to determine expression for survival comparison may be insufficiently quantitative to see a significant difference. Limitations in the amount of tissue did not allow for direct RNA or protein measurement in each tumor. Lastly, these data do not give any information about the role of hRad17 in ovarian cancer.

\section{Conclusions}

hRad17 is over-expressed in a majority of epithelial ovarian cancers. Furthermore, this over-expression varies by subtype suggesting a role in the pathogenesis and behavior of these types. Functional studies are needed to determine the potential role of this protein in the development of ovarian cancer.

\section{List of Abbreviations used}

CDNA: complimentary DNA; HOSE: human ovarian surface epithelium cell line; RT-PCR: real time polymerase chain reaction; GAPDH: Glyceraldehyde 3phosphate dehydrogenase; SDS-PAGE: sodium dodecyl sulfate polyacrylamide gel electrophoresis; PVDF: polyvinylidene fluoride; TBST: Trisbuffered saline Tween-20; TBS: Tris-buffered saline; BSA: Bovine serum albumin.

\section{Acknowledgements}

This study was supported in part by Dana-Farber/Harvard Cancer Center Ovarian Cancer SPORE grant P50CA105009 and R33CA103595 from National Institute of Health Department of Health and Human Services, Gillette Center For Women's Cancer, Adler Foundation, Inc., Edgar Astrove Fund, the Ovarian Cancer Research Fund, Inc., the Morse Family Fund, the Natalie Pihl Fund, the Ruth N. White Research Fellowship, and the Friends of Dana Farber Cancer Institute. We would also like to thank Dr. Lan Bo Chen of the Department of Cancer Biology, Dana Farber Cancer Institute and Harvard Medical School for providing the hRad17 monoclonal antibody.

\section{Author details}

'Division of Gynecologic Oncology, Department of Obstetrics, Gynecology and Reproductive Biology, Brigham and Women's Hospital, Harvard Medical School, Boston, MA, USA. 'Division of Gynecologic Oncology, Department of Obstetrics and Gynecology, Medical University of South Carolina, Charleston, SC, USA. ${ }^{3}$ Division of Gynecologic Oncology, Department of Obstetrics and Gynecology, Baylor University Medical Center, Dallas, TX, USA. ${ }^{4}$ Centre for Translational Oncology, Institute of Cancer and the CR-UK Clinical Centre, Barts and the London Queen Mary's School of Medicine and Dentistry, London, UK. ${ }^{5}$ Department of Pathology, Brigham and Women's Hospital, Harvard Medical School, Boston, MA, USA. ${ }^{6}$ Department of Gynecologic 
Oncology, University of Texas MD Anderson Cancer Center, Houston, TX, USA.

\section{Authors' contributions}

JY performed the immunohistochemistry, western blot analysis, data analysis, and drafted the manuscript. CK participated in the acquisition of samples, clinical data analysis, western blot analysis, and RT-PCR. JK participated in the acquisition of samples, western blot analysis, and RT-PCR. WW reviewed all of the slides for pathologic confirmation of cell type and provided all of the samples. MM participated in study design, acquisition of samples, and acquisition of clinical data. RB participated in study design, acquisition of samples, and acquisition of clinical data. SM conceived of the study design, participated in immunohistochemistry, western blot, data analysis, and manuscript writing. All authors critically reviewed drafts of the manuscript and have approved the final version for publication.

\section{Competing interests}

The authors declare that they have no competing interests.

Received: 18 January 2011 Accepted: 30 March 2011

Published: 30 March 2011

\section{References}

1. Jemal A, Siegel R, Ward E, Murray T, Xu J, Smigal C, Thun MJ: Cancer statistics, 2006. CA Cancer J Clin 2006, 56:106-130.

2. Rosen DG, Wang L, Atkinson JN, Yu Y, Lu KH, Diamandis EP, Hellstrom I, Mok SC, Liu J, Bast RC Jr: Potential markers that complement expression of CA125 in epithelial ovarian cancer. Gynecol Oncol 2005, 99:267-277.

3. Schorge JO, Drake RD, Lee H, Skates SJ, Rajanbabu R, Miller DS, Kim J-H, Cramer DW, Berkowitz RS, Mok SC: Osteopontin as an adjunct to CA125 in detecting recurrent ovarian cancer. Clin Cancer Res 2004, 10:3474-3478.

4. Mok SC, Chao J, Skates S, Wong K, Yiu GK, Muto MG, Berkowitz RS, Cramer DW: Prostasin, a potential serum marker for ovarian cancer: identification through microarray technology. J Natl Cancer Inst 2001, 93:1458-1464.

5. Bandera CA, Ye B, Mok SC: New technologies for the identification of markers for early detection of ovarian cancer. Curr Opin Obstet Gynecol 2003, 15:51-55.

6. Wong KK, Cheng RS, Mok SC: Identification of differentially expressed genes from ovarian cancer cells by MICROMAX cDNA microarray system. Biotechniques 2001, 30:670-675.

7. Bao S, Chang MS, Auclair D, Sun Y, Wang Y, Wong WK, Zhang J, Liu Y, Qian X, Sutherland R, et al: HRad17, a human homologue of the Schizosaccharomyces pombe checkpoint gene rad17, is overexpressed in colon carcinoma. Cancer Res 1999, 59:2023-2028.

8. Parker $A E$, Van de Weyer I, Laus MC, Verhasselt $P$, Luyten WH: Identification of a human homologue of the Schizosaccharomyces pombe rad17+ checkpoint gene.[erratum appears in J Biol Chem 1999 Aug 20;274 (34):24438]. J Biol Chem 1998, 273:18340-18346.

9. Li L, Peterson CA, Kanter-Smoler G, Wei YF, Ramagli LS, Sunnerhagen P, Siciliano MJ, Legerski RJ: hRAD17, a structural homolog of the Schizosaccharomyces pombe RAD17 cell cycle checkpoint gene, stimulates p53 accumulation. Oncogene 1999, 18:1689-1699.

10. Post SM, Tomkinson AE, Lee EYHP: The human checkpoint Rad protein Rad17 is chromatin-associated throughout the cell cycle, localizes to DNA replication sites, and interacts with DNA polymerase epsilon. Nucleic Acids Res 2003, 31:5568-5575.

11. Chang MS, Sasaki H, Campbell MS, Kraeft SK, Sutherland R, Yang CY, Liu Y, Auclair D, Hao L, Sonoda H, et al: HRad17 colocalizes with NHP2L1 in the nucleolus and redistributes after UV irradiation. J Biol Chem 1999, 274:36544-36549.

12. Bao S, Tibbetts RS, Brumbaugh KM, Fang Y, Richardson DA, Ali A, Chen SM, Abraham RT, Wang XF: ATR/ATM-mediated phosphorylation of human Rad17 is required for genotoxic stress responses. Nature 2001, 411:969-974.

13. Nabetani A, Yokoyama O, Ishikawa F: Localization of hRad9, hHus1, hRad1, and hRad17 and caffeine-sensitive DNA replication at the alternative lengthening of telomeres-associated promyelocytic leukemia body. J Biol Chem 2004, 279:25849-25857.
14. Wang X, Wang L, Callister MD, Putnam JB, Mao L, Li L: Human Rad17 is phosphorylated upon DNA damage and also overexpressed in primary non-small cell lung cancer tissues. Cancer Res 2001, 61:7417-7421.

15. Post $S$, Weng YC, Cimprich $K$, Chen LB, Xu Y, Lee EY: Phosphorylation of serines 635 and 645 of human Rad17 is cell cycle regulated and is required for $\mathrm{G}(1) / \mathrm{S}$ checkpoint activation in response to DNA damage. Proc Natl Acad Sci USA 2001, 98:13102-13107.

16. Bermudez VP, Lindsey-Boltz LA, Cesare AJ, Maniwa Y, Griffith JD, Hurwitz J, Sancar A: Loading of the human 9-1-1 checkpoint complex onto DNA by the checkpoint clamp loader hRad17-replication factor $\mathrm{C}$ complex in vitro. Proc Natl Acad Sci USA 2003, 100:1633-1638.

17. Rauen M, Burtelow MA, Dufault VM, Karnitz LM: The human checkpoint protein hRad17 interacts with the PCNA-like proteins hRad1, hHus1, and hRad9. J Biol Chem 2000, 275:29767-29771.

18. Griffith JD, Lindsey-Boltz LA, Sancar A: Structures of the human Rad17replication factor $C$ and checkpoint Rad 9-1-1 complexes visualized by glycerol spray/low voltage microscopy. J Biol Chem 2002, 277:15233-15236.

19. Lindsey-Boltz LA, Bermudez VP, Hurwitz J, Sancar A: Purification and characterization of human DNA damage checkpoint Rad complexes. Proc Natl Acad Sci USA 2001, 98:11236-11241.

20. Song W, Levin DS, Varkey J, Post S, Bermudez VP, Hurwitz J, Tomkinson AE: A conserved physical and functional interaction between the cell cycle checkpoint clamp loader and DNA ligase I of eukaryotes. J Biol Chem 2007, 282:22721-22730.

21. Bao S, Lu T, Wang X, Zheng H, Wang L-E, Wei Q, Hittelman WN, Li L: Disruption of the Rad9/Rad1/Hus1 (9-1-1) complex leads to checkpoint signaling and replication defects. Oncogene 2004, 23:5586-5593.

22. Tsao C-C, Geisen C, Abraham RT: Interaction between human MCM7 and Rad17 proteins is required for replication checkpoint signaling. Embo $\mathrm{J}$ 2004, 23:4660-4669.

23. Kawabe T: G2 checkpoint abrogators as anticancer drugs. Mol Cancer Ther 2004, 3:513-519.

24. Kataoka A, Sadanaga N, Mimori K, Ueo H, Barnard GF, Sugimachi K, Auclair D, Chen LB, Mori M: Overexpression of HRad17 mRNA in human breast cancer: correlation with lymph node metastasis. Clin Cancer Res 2001, 7:2815-2820.

25. Tsao SW, Mok SC, Fey EG, Fletcher JA, Wan TS, Chew EC, Muto MG, Knapp RC, Berkowitz RS: Characterization of human ovarian surface epithelial cells immortalized by human papilloma viral oncogenes (HPVE6E7 ORFs). Exp Cell Res 1995, 218:499-507.

26. Ni X, Zhang W, Huang KC, Wang Y, Ng SK, Mok SC, Berkowitz RS, Ng SW: Characterisation of human kallikrein 6/protease $M$ expression in ovarian cancer.[erratum appears in Br J Cancer. 2005 Mar 14;92(5):983]. Br J Cancer 2004, 91:725-731.

27. Sasaki H, Chen LB, Auclair D, Moriyama S, Kaji M, Fukai I, Kiriyama M, Yamakawa Y, Fujii Y: Overexpression of Hrad17 gene in non-small cell lung cancers correlated with lymph node metastasis. Lung Cancer 2001, 34:47-52.

28. Zhao M, Begum S, Ha PK, Westra W, Califano J: Downregulation of RAD17 in head and neck cancer. Head Neck 2008, 30:35-42

doi:10.1186/1757-2215-4-6

Cite this article as: Young et al:: Differential hRad17 expression by histologic subtype of ovarian cancer. Journal of Ovarian Research 2011 4:6. 